\title{
Protective Effect of Garlic Extract Against Pentylenetetrazole Induced Seizures
}

\author{
Romany Helmy Thabet ${ }^{1 *}$, Arwa Safar S Alshaibany ${ }^{2}$, Reem Jazaa M Alenezi ${ }^{2}$, Aeshah Marshad A Alanazi ${ }^{2}$ \\ ${ }^{1 * A s s i s t a n t ~ P r o f e s s o r, ~ P h a r m a c o l o g y ~ D e p a r t m e n t, ~ F a c u l t y ~ o f ~ M e d i c i n e, ~ N o r t h e r n ~ B o r d e r ~ U n i v e r s i t y, ~}$ \\ Arar, Saudi Arabia. \\ ${ }^{2}$ Medical Student, Faculty of Medicine, Northern Border University, Arar, Saudi Arabia.
}

\begin{abstract}
Background and Aims: Previous studies in literature reported that compared with fresh preparations of garlic and aged garlic extract (AGE) contain high amount of antioxidants and protect against cancer, aging and many cardiovascular diseases. The present work investigates effect of AGE against pentylenetetrazole (PTZ)-induced convulsions and brain levels of Gamma amino butyric acid (GABA).

Methods: The least and median convulsive $\left(C D_{50}\right)$ doses of PTZ were determined either alone or after pretreatment with AGE. The forebrain levels of the neurotransmitter GABA have been measured in rats given PTZ, alone and after pretreatment with AGE.

Results: The present study showed that AGE pretreatment elicited a dose dependent protection of rats against PTZinduced seizures. AGE in a dose of $400 \mathrm{mg} 60$ minutes prior to $60 \mathrm{mg} / \mathrm{kg}$ PTZ produced $80 \%$ decrease in incidence of seizures. AGE pretreatment produced significant elevation of the median convulsive dose (CD50) of PTZ from $47 \mathrm{mg} / \mathrm{kg}$ to $55 \mathrm{mg} / \mathrm{kg}$. Results have shown that cellular brain GABA concentrations decreased significantly $(P<0.05)$ in rats given $400 \mathrm{mg} / \mathrm{kg}$ AGE 60 minutes prior to $60 \mathrm{mg} / \mathrm{kg}$ PTZ compared
\end{abstract}

\section{INTRODUCTION}

Garlic is considered a component of traditional medicine that has long been used for hypertension ${ }^{1}$ and diabetes. ${ }^{2,3}$ It is a health protecting food owed to its antioxidant/anti-inflammatory and neuroprotective activities. Aged garlic extracts (AGE), compared with fresh garlic preparations, has no odor, contains higher quantities of antioxidants and protects against cancer, many cardiovascular diseases, stroke, Alzheimer's disease and other aging disorders. ${ }^{4}$ To get higher quantities of antioxidants, AGE is prepared by extracting and aging fresh garlic at room temperature for about one and half years in $20 \%$ ethanol. AGE contains flavonoids, allixin, selenium and water-soluble sulfur antioxidant substances with high bioavailability such as Sallylmercaptocysteine (SAMC) and S-allyl cysteine (SAC) , ${ }^{5,6}$

Pentylenetetrazole (PTZ) is a prompt and powerful central nervous system (CNS) stimulant. The principal target cells for PTZ are those in the medulla and midbrain. In larger doses its action ascends to the cerebral cortex and descends to the spinal cord. with control and PTZ-treated groups.

Conclusion: The present work suggests a potential neuroprotective effect of AGE against PTZ-induced seizures that may be explained by increasing brain levels of the major central inhibitory neurotransmitter GABA.

Key Words: Pentylenetetrazole, Seizures, Gamma amino butyric acid (GABA).

\section{${ }^{*}$ Correspondence to:}

Dr. Romany HelmyThabet,

Assistant Professor, Pharmacology Department Northern Border University, Arar, Saudi Arabia.

Article History:

Received: 24-08-2016, Revised: 12-09-2016, Accepted: 26-09-2016

\begin{tabular}{|l|c|}
\hline \multicolumn{2}{|c|}{ Access this article online } \\
\hline Website: & Quick Response code \\
www.ijmrp.com & \\
\hline DOI: & \\
10.21276/ijmrp.2016.2.5.033 & \\
\hline
\end{tabular}

In experimental animals, threshold convulsive doses of the drug produce motor activity characterized by forelimb and jaw clonus. This convulsion resembles that produced by electrical stimulation of the brain with current of just threshold intensity. With slightly larger doses of PTZ, generalized, asynchronized clonic movements are observed.

This phase is usually superseded by a tonic convulsion; such a convulsion resembles that produced by maximal brain stimulation in that the movements of the limbs consist of flexion followed by extension. ${ }^{7}$

In the past, PTZ was used therapeutically as a respiratory stimulant in emergencies and in the treatment of mental disorders (as a shock therapy), but it is no longer used as its margin of safety is too low. PTZ can be used diagnostically. When given in very small amounts, it will produce seizure in a person with epilepsy. Its wide use is to induce seizures for screening of anticonvulsant drugs. ${ }^{8}$ 
$\mathrm{p}$-aminobutyric acid (GABA) is the major neurotransmitter for fast inhibitory synaptic transmission. The GABAergic system is a target for a wide range of drugs including anxiolytics, sedativehypnotics, general anesthetics, and anticonvulsants. ${ }^{9}$

This study provides an insight on the effect of administration of AGE prior to challenging rats with the known convulsing agent PTZ. In the present work, the least and median convulsive dose (CD50) of PTZ was determined either alone or after pretreatment with AGE. The study also investigates the effect of pretreatment of rats with AGE on the central levels of the major inhibitory neurotransmitter GABA in rats after induction of convulsions by PTZ.

\section{MATERIALS AND METHODS}

\section{Chemicals}

PTZ (Sigma, USA) was dissolved in distilled water. Liquid suspension of AGE (240 mg AGE/ml) was purchased from Wakunaga, USA and administered intraperitoneally at doses of $200 \mathrm{mg} / \mathrm{kg}$ and $400 \mathrm{mg} / \mathrm{kg}$.

\section{Animals}

Adult male rats weighing 150-200g were used. The animals were group housed in plastic cages and maintained under standard laboratory conditions with a natural light-dark cycle. Rats were left to acclimatize to the environment for at least a week before the experiments. Food and water were allowed ad libitum.

\section{Pentylenetetrazol seizures}

3 groups of rats each was comprised of 5 animals.

\section{Treatment schedules}

Group A: Was given PTZ i.p in a dose of $30 \mathrm{mg} / \mathrm{kg}$.

Group B: Was given PTZ i.p in a dose of $60 \mathrm{mg} / \mathrm{kg}$.

Group C: Was given PTZ i.p in a dose of $70 \mathrm{mg} / \mathrm{kg}$.

Doses were selected according to Malhotra and Gupta. ${ }^{10}$ The animals were observed for 30 minutes after PTZ challenge for incidence, latencies and character of seizures.

\section{Determination of $C_{50}$ of PTZ}

Computations of the median convulsive dose and its confidence limits for PTZ were proceeded according to the method of Litchfield and Wilcoxon. ${ }^{11}$ Groups of 10 rats were injected with graded doses of PTZ. Percentage incidence of seizures in each group was determined during a period of 30 minutes after drug administration.

\section{Effect of AGE pretreatment on PTZ induced seizures \\ 6 groups of rats each was comprised of 10 animals. \\ Treatment schedules}

Group A: Was given PTZ i.p in a dose of $60 \mathrm{mg} / \mathrm{kg}$.

Group B: Was given AGE i.p in a dose of $200 \mathrm{mg} / \mathrm{kg} 5$ minutes before PTZ challenge.

Group C: Was given AGE i.p in a dose of $400 \mathrm{mg} / \mathrm{kg} 5$ minutes before PTZ challenge.

Group D: Was given AGE i.p in a dose of $200 \mathrm{mg} / \mathrm{kg} 15$ minutes before PTZ challenge.

Group E: Was given AGE i.p in a dose of $400 \mathrm{mg} / \mathrm{kg} 15$ minutes before PTZ challenge.

Group F: Was given AGE i.p in a dose of $400 \mathrm{mg} / \mathrm{kg} 60$ minutes before PTZ challenge.

Animals were observed for 30 minutes after PTZ challenge for incidence of myoclonic jerks and generalized tonic clonic seizures. Dose of PTZ was selected according to results obtained in the previous step, while doses of AGE were selected according to preliminary experiments.

\section{Effect of AGE pretreatment on $\mathrm{CD}_{50}$ of PTZ}

Groups of 10 rats were injected i.p with graded doses of PTZ 5 minutes after their pretreatment with AGE injected i.p in a dose of $400 \mathrm{mg} / \mathrm{kg}$. Percentage incidence of seizures in each group was determined during a period of 30 minutes after PTZ administration. Computation of the median convulsive dose $\left(C D_{50}\right)$ and its confidence limits for PTZ were proceeded according to the method of Litchfield and Wilcoxon. ${ }^{11}$

\section{Measurement of GABA levels in rat forebrain Animal protocol and rat brain extraction}

GABA levels in forebrains of the following groups of rats were measured:

1. Control normal rats weighing $150-200 \mathrm{~g}$ (negative group) comprised of 5 animals.

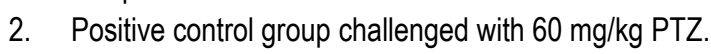

3. Rats given AGE i.p in a dose of $400 \mathrm{mg} / \mathrm{kg} 5$ minutes prior to $60 \mathrm{mg} / \mathrm{kg}$ PTZ.

4. Rats given AGE i.p in a dose of $400 \mathrm{mg} / \mathrm{kg} 15$ minutes prior to $60 \mathrm{mg} / \mathrm{kg}$ PTZ.

5. Rats given AGE i.p in a dose of $400 \mathrm{mg} / \mathrm{kg} 60$ minutes prior to $60 \mathrm{mg} / \mathrm{kg}$ PTZ

According to the method described by Laura and Ognen, rats were decapitated and brains were quickly removed ( $<90$ seconds) rostral to the cerebellum and frozen in liquid nitrogen. Frozen brains were extracted in $3.5 \mathrm{ml}$ cold $12 \%$ perchloric acid (PCA) stock solution containing $7.7 \mathrm{mM}$ dichloracetic acid (Sigma) and centrifuged at $3200 \times \mathrm{g}$ for 15 minutes at $4{ }^{\circ} \mathrm{C}$. The neutral supernatant was centrifuged at $3200 \times \mathrm{g}$ for 10 minutes at $4{ }^{\circ} \mathrm{C}$. 0.5 $\mathrm{g}$ chelating resin (Sigma) was added to the neutral solution which is then filtered and lyophilised. The dried powder was dissolved in neutral $50 \mathrm{mM}$ deuterated phosphate in D2O containing $2 \mathrm{mM}$ isopropanol. ${ }^{12}$

\section{Statistical analysis of the results}

CD50 values and analysis of the results obtained in the convulsive tests were calculated by fitting the data by linear regression analysis as described by Litchfield and Wilcoxon (1949). Significance tests of CD50 values of theophylline, alone and after pretreatment with Ginger extract in rats were determined by using $95 \%$ confidence limits according to Snedecor. ${ }^{13}$ The significance of the differences was determined using the student's t-test. The difference was regarded as significant when $P<0.05$ and as a highly significant when $P<0.01$.

\section{RESULTS}

\section{Pentylenetetrazole seizures}

Group A (PTZ $30 \mathrm{mg} / \mathrm{kg}$ ): No convulsions were elicited.

Group B (PTZ $60 \mathrm{mg} / \mathrm{kg}$ ): Three rats showed intermittent clonic convulsions with tail erection. The latencies of incidence of convulsions differed (5 - 10 minutes post-injection). These convulsions continued for about 1 minute. One rat showed intermittent clonic convulsions 5 minutes post-injection followed, within seconds, by generalized tonic convulsions then died. One animal showed no convulsions and survived.

Group C (PTZ $70 \mathrm{mg} / \mathrm{kg}$ ): Generalized tonic-clonic convulsions occurred in the 5 animals 1 minute after injection of PTZ and within seconds; 3 of them died. So, in view of these observations, 
PTZ was used in a dose of $60 \mathrm{mg} / \mathrm{kg}$ to elicit seizures (clonic intermittent followed by generalized tonic-clonic). This dose was used in the following steps after treating rats with adenosine and its agonists.

\section{Determination of CD50 of PTZ}

The median convulsive dose $\left(C D_{50}\right)$ of Pentylenetetrazole injected intraperitoneally into rats was equivalent to 47 (40.52 - 54.52) $\mathrm{mg} / \mathrm{kg}$.

Table 1: CD50 and its 95\% confidence limits of i.p PTZ

\begin{tabular}{lccccc}
\hline Dose & Convulsed & Observed & Expected & Observed & Contribution to \\
& - & & & - & \\
\hline (mg/kg) & tested & \% convulsed & \% convulsed & expected & (Chi) $^{2}$ \\
$\mathbf{3 0}$ & $0 / 10$ & 2 & 6 & 4 & 0.0280 \\
$\mathbf{4 0}$ & $3 / 10$ & 30 & 30 & 0 & 0.0000 \\
$\mathbf{5 0}$ & $6 / 10$ & 60 & 60 & 0 & 0.0000 \\
$\mathbf{6 0}$ & $8 / 10$ & 97.7 & 92 & 2 & 0.0028 \\
$\mathbf{7 0}$ & $10 / 10$ & & & 4.7 & 0.0350 \\
& & & & Total & 0.0658 \\
\hline
\end{tabular}

Total animals $=50$

Number of doses $=5$

Animals $/$ doses $=50 / 5=10$

$(\text { Chi })^{2}=0.0658 \times 10=0.658$

Degrees of freedom $=5-2=3$

Tabulated $(\text { Chi })^{2}$ for $n$ of 3 from table (13) $=7.82$

.. $(\text { Chi })^{2}$ calculated is less than $(\mathrm{Chi})^{2}$ tabulated

$\therefore$ The data are not significantly heterogenous

$\mathrm{CD}_{84}=62 \mathrm{mg} / \mathrm{kg}$

$\mathrm{CD}_{50}=47 \mathrm{mg} / \mathrm{kg}$

$\mathrm{CD}_{16}=35 \mathrm{mg} / \mathrm{kg}$

$\mathrm{S}=\frac{62 / 47+47 / 35}{2}=\frac{1.32+1.34}{2}=\frac{2.66}{2}=1.33$

$\bar{N}=30$

Exponent $=2.77 / \sqrt{30}=2.77 / 5.47=0.51$

$\mathrm{FCD}_{50}=1.33^{0.51}=1.16$

$\mathrm{CD}_{50} \times \mathrm{FCD}_{50}=54.52$

$\mathrm{CD}_{50} / \mathrm{FCD}_{50}=40.52$

$\therefore C D_{50}$ and its $95 \%$ confidence limits $=47(40.52-54.52) \mathrm{mg} / \mathrm{kg}$.

\section{Effect of AGE pretreatment on PTZ-induced seizures}

Group A (PTZ $60 \mathrm{mg} / \mathrm{kg}$ ):

Within 3-5 minutes there were myoclonic jerks that continued for about 1 minute. This was followed by generalized clonic convulsions with appearance of tail erection in some ones. Generalized seizures continued for a brief duration (less than 1 minute) and then the animals died.

Group B (AGE $200 \mathrm{mg} / \mathrm{kg} 5$ minutes before PTZ $60 \mathrm{mg} / \mathrm{kg}$ ): Myoclonic seizures were observed in 8 rats about 20 minutes after injection of PTZ and continued for about 1 minute. In 6 out of the eight rats, seizures became generalized for brief seconds and the animals then survived. Two rats showed irritability without incidence of convulsions.

Group C (AGE $200 \mathrm{mg} / \mathrm{kg} 15$ minutes before PTZ $60 \mathrm{mg} / \mathrm{kg}$ ): Myoclonic intermittent convulsions happened in 5 rats about 20 minutes after injection of PTZ and within 30 seconds became generalized tonic-clonic seizures and the animals died later.

Group D (AGE $400 \mathrm{mg} / \mathrm{kg} 5$ minutes before PTZ $60 \mathrm{mg} / \mathrm{kg}$ ): Myoclonic convulsions occurred in 4 rats about 15 minutes after injection of PTZ and continued for about 1 minute then became generalized clonic seizures for 30 seconds and the animals survived.

Group E (AGE $400 \mathrm{mg} / \mathrm{kg} 15$ minutes before PTZ $60 \mathrm{mg} / \mathrm{kg}$ ): Myoclonic seizures happened in 3 rats about 30 minutes after injection of PTZ and continued for about 30 seconds. One of the previous 3 rats showed generalized convulsions with tail erection for about 10 seconds and survived. The remainder rats showed no abnormality.

Group F (AGE $400 \mathrm{mg} / \mathrm{kg} 60$ minutes before PTZ $60 \mathrm{mg} / \mathrm{kg}$ ): Myoclonic seizures were observed in two rats 30 minutes after PTZ challenge and lasted for about 1 minute. Then it became generalized clonic in one of the two rats. The generalized convulsions continued for less than one minute and the animals convulsed animals survived.

\section{Effect of AGE pretreatment on CD50 of PTZ}

The median convulsive dose of PTZ injected intraperitoneally into rats 5 minutes after AGE pretreatment was equivalent to 55 (46.6 - 64.9) $\mathrm{mg} / \mathrm{kg}$.

Table 2: CD50 and its 95\% confidence limits of i.p. PTZ injected following AGE pretreatment.

\begin{tabular}{cccccc}
\hline Dose & Convulsed & Observed & Expected & Observed & Contribution to \\
& ---- & & & expected & $($ Chi) \\
\hline (mg/kg) & tested & \% convulsed & convulsed & 3.4 & 0.0250 \\
$\mathbf{3 0}$ & $0 / 10$ & 1.6 & 5 & 0 & 0.0000 \\
$\mathbf{4 0}$ & $2 / 10$ & 20 & 40 & 0 & 0.0000 \\
$\mathbf{5 0}$ & $4 / 10$ & 60 & 60 & 0 & 0.0000 \\
$\mathbf{6 0}$ & $6 / 10$ & 80 & 74 & 6 & 0.0200 \\
$\mathbf{7 0}$ & $8 / 10$ & 95.3 & 85 & 10.3 & 0.0800 \\
$\mathbf{8 0}$ & $10 / 10$ & & & Total & $\mathbf{0 . 1 2 5}$ \\
\hline
\end{tabular}


Romany Helmy Thabet et al. Garlic extract vs. PTZ-induced seizures

Total animals $=60$

Number of doses $=6$

Animals $/$ doses $=60 / 6=10$

$(\text { Chi })^{2}=0.125 \times 10=0.25$

Degrees of freedom $=6-2=4$

Tabulated $(\text { Chi })^{2}$ for $n$ of 4 from table (13) $=9.49$

.. (Chi) $)^{2}$ calculated is less than $(\mathrm{Chi})^{2}$ tabulated

$\therefore$ The data are not significantly heterogenous

$\mathrm{CD}_{84}=79$

$\mathrm{CD}_{50}=55$

$\mathrm{CD}_{16}=38$

$\mathrm{S}=\frac{79 / 55+55 / 38}{2}=\frac{1.44+1.45}{2}=\frac{2.89}{2}=1.44$
$\bar{N}=40$

Exponent $=2.77 / \sqrt{40}=2.77 / 6.32=0.44$

$\mathrm{FCD}_{50}=1.440 .44=1.18$

$\mathrm{CD}_{50} \times \mathrm{FCD}_{50}=64.9$

$\mathrm{CD}_{50} / \mathrm{FCD}_{50}=46.6$

$\therefore \mathrm{CD}_{50}$ and its $95 \%$ confidence limits $=55(46.6-64.9) \mathrm{mg} / \mathrm{kg}$

\section{Glutamate and GABA levels in rat forebrain}

Cellular brain GABA levels increased significantly $(P<0.05)$ in rats given AGE i.p in doses of $400 \mathrm{mg} / \mathrm{kg} 5,15$ and 60 minutes prior to $60 \mathrm{mg} / \mathrm{kg}$ PTZ compared with negative and PTZ -treated groups.

Table 3: GABA Brain levels

\begin{tabular}{|c|c|}
\hline Group & GABA level \\
\hline Negative control & $2.18 \pm 0.04$ \\
\hline Positive control (PTZ 60mg/kg) & $1.65 \pm 0.02^{*}$ \\
\hline $\begin{array}{l}\text { AGE i.p in a dose of } 400 \mathrm{mg} / \mathrm{kg} 5 \text { minutes prior } \\
\text { to } 60 \mathrm{mg} / \mathrm{kg} \mathrm{PTZ}\end{array}$ & $2.52 \pm 0.01^{*} \#$ \\
\hline $\begin{array}{l}\text { AGE i.p in a dose of } 400 \mathrm{mg} / \mathrm{kg} 15 \text { minutes prior } \\
\text { to } 60 \mathrm{mg} / \mathrm{kg} \text { PTZ }\end{array}$ & $2.48 \pm 0.02^{\star} \#$ \\
\hline $\begin{array}{l}\text { AGE in a dose of } 400 \mathrm{mg} / \mathrm{kg} 60 \text { minutes prior to } \\
60 \mathrm{mg} / \mathrm{kg} \text { PTZ }\end{array}$ & $2.64 \pm 0.01^{*} \#$ \\
\hline
\end{tabular}

Values represent the mean concentrations $(\mathrm{mM})$ with \pm SEM.

${ }^{*} P<0.05$ versus negative control.

$\# P<0.05$ versus PTZ.

\section{DISCUSSION}

Garlic and its preparations have been long used to maintain good health and as a component of traditional medicine for treatment and protection against many cardiovascular and metabolic disorders such as hypertension, atherosclerosis, hyperlipidemia, thromboembolism, degenerative diseases as dementia, cancer and diabetes mellitus. ${ }^{14}$ Aged garlic extract is available with known dose concentration over the counter in a suitable form for intake.

Contrary to fresh garlic; AGE is highly acceptable, has no odor with minimal gastrointestinal troubles. It is prepared by storing macerated sliced fresh garlic at room temperature for 20 months. Aging of garlic increases the content of water-soluble compounds and decreases the oil-soluble sulfur compounds that have the unpleasant odour. ${ }^{15}$ AGE contains high amount of S-allylcysteine (SAC) and S-allylmercaptocysteine (SAMC) in addition to stable lipid-soluble allyl sulfides, flavonoids and saponins. ${ }^{16}$

Pentylenetetrazole is a known CNS stimulant widely used for screening of anticonvulsant drugs. Stimulant effects of PTZ may also be due to the capacity to reduce the impact of GABA on chloride ion conductance at concentrations that do not alter resting neuronal membrane conductance in the absence of GABA. ${ }^{17}$ In addition, PTZ appears to interact with binding sites for picrotoxin and to block the enhanced binding of GABA and benzodiazepines that is produced by hypnotic barbiturates. ${ }^{18}$ While direct excitatory effects have not been excluded, it would appear that a major action of PTZ may be to reduce GABA-ergic inhibition, thereby enhancing CNS excitability.
Our study demonstrated that AGE, in a dose of $400 \mathrm{mg} / \mathrm{kg}$ if given 5 minutes before PTZ in a dose of $60 \mathrm{mg} / \mathrm{kg}$, was partially effective in protection against PTZ-induced seizures as evidenced by decreased number of convulsing rats and an increased latency before convulsions.

It was also observed that AGE $(400 \mathrm{mg} / \mathrm{kg})$ pretreatment produced significant elevation of the median convulsive dose (CD50) of PTZ in rats from $47 \mathrm{mg} / \mathrm{kg}$ to $55 \mathrm{mg} / \mathrm{kg}$. The anticonvulsant effect of age observed is this work may be explained by the high content of antioxidants. This is in agreement with Gupta et al., 2002 have demonstrated that resveratrol, a polyphenolic compound with potent antioxidant activity, when administered 20 minutes prior to convulsive challenge with PTZ (60 mg/kg i.p), it dose-dependently reduced the percentage of generalized tonic-clonic convulsions. ${ }^{19}$ More recently, OrozcoIbarra and his colleagues reported that AGE and its main constituent S-allylcysteine (SAC) are natural antioxidants that have protective effects against cerebral ischemia. ${ }^{20}$

As aforementioned, the enhancing CNS excitability effect of PTZ may be owed to reduction of GABA-ergic inhibition, the present work illustrated how administrations of AGE prior to induction of convulsions by PTZ; alter the cellular brain levels of the major inhibitory neurotransmitter GABA. Results have shown significant increase in GABA levels $(P<0.05)$ in rats given AGE 5 minutes prior to $60 \mathrm{mg} / \mathrm{kg}$ PTZ compared with control group and PTZtreated group. 
The present study is in agreement with other studies in literature with regards to effect of garlic extract on GABAergic neurotransmission. Dinesh and Vaibhav, 2008 have been reported that garlic extract showed antidepressant-like activity through interaction with adrenergic, dopaminergic, serotonergic and GABAergic systems. ${ }^{21}$ Another more recent study by Neeraj and Dinesh, 2016 mentioned showed that garlic extract possesses an anxiolytic effect and increases GABA brain levels in mice. ${ }^{22}$

\section{CONCLUSION}

Based on the results obtained in the present study, it seems that AGE may have a notable protective effect against PTZ-induced convulsions that may be owed to its antioxidant activities or enhancement of the inhibitory GABA neurotransmission.

\section{REFERENCES}

1. R. S. Rivlin, "Historical perspective on the use of garlic," Journal of Nutrition 2001; 131(3), pp. 951S-954S.

2. E. Ayaz and H. C. Alpsoy, Garlic (Allium sativum) and traditional medicine, Türkiye Parazitolojii Dergisi 2007, 31(2), pp. 145-149.

3. W. L. Li, H. C. Zheng, J. Bukuru, and N. De Kimpe, Natural medicines used in the traditional Chinese medical system for therapy of diabetes mellitus, Journal of Ethnopharmacology 2004, 92(1), pp. 1-21.

4. Cemil B, Gokce EC, Kahveci R, Gokce A, Aksoy N, Sargon MF, Erdogan B, Kosem B. Aged Garlic Extract Attenuates Neuronal Injury in a Rat Model of Spinal Cord Ischemia/Reperfusion Injury. J Med Food. 2016; 19(6):601-6.

5. Amagase $\mathrm{H}$, Petesch $\mathrm{BL}$, Matsuura $\mathrm{H}$, Kasuga $\mathrm{S}$, Itakura $\mathrm{Y}$. Intake of garlic and its bioactive components. J Nutr. 2001; 131 : 955S-62S.

6. Lawson LD. The composition and chemistry of garlic cloves and processed garlic. In: Koch HP, Lawson LD, editors. The Science and Therapeutic Application of Allium sativum L. and Related Species. Baltimore: Williams and Wilkins; 1996. p. 37-107.

7. Lewin $\mathrm{J}$ and Esplin DW. Analysis of the spinal excitatory action of pentylenetetrazole. J. Pharmacol. Exp. Ther 1961; 132: 245 250.

8. Esplin DW and Curto EM. Effects of trimethadione on synaptic transmission in the spinal cord; antagonism of trimethadione and pentylenetetrazol. J. Pharmacol. Exp. Ther.1957; 121: 457 - 467.

9. Macdonald RL, Olsen RW. GABAA receptor channels. Annu Rev Neurosci 1994; 17: 569-602.

10. Malhotra J and Gupta YK. Effect of adenosine receptor modulation and pentylenetetrazole-induced seizures in rats. Br. J Pharmacol 1997; 120: 282-288.

11. Litchfield JT and Wilcoxon F. A simplified method of evaluating dose effect experiments. J Pharmacol Exp Ther. 1949; 96:99-113. 12. Laura D E, Ognen A.C P. Acute effects of gabapentin and pregabalin on rat forebrain cellular GABA, glutamate, and glutamine concentrations. Seizures July 2003; 12(5), 300-306.
13. Snedecor GW, William G Cochran (1967): "Statistical methods" lowa state university press.

14. Lawson L D. Garlic: a review of its medicinal effects and indicated active compounds. Phytomedicines of Europe. Chemistry and Biological activity. 1998; series 691:176-209.

15. Amagase $H$, Petesch BL, Matsuura $H$, Kasuga $S$, Itakura $Y$. Intake of garlic and its bioactive components. J Nutr. 2001; 131: 955S-62.

16. Wakunaga Company: http://www.kyolic.com/the-kyolicdifference/. [Accessed on 19 Jan 2016].

17. Schofield CN. Antagonism of t-aminobutyric acid and muscimol by picrotoxin, bicuculine, strychnine, bemegride, leptazol, d-tubocurarine and theophylline in the isolated olfactory cortex. Arch. Pharm. (weinheim) 1982; 318: 274 - 280.

18. Olsen RW. The GABA post synaptic membrane receptor-ion ophore complex: site of action of convulsant and anticonvulsant drugs. Mol. Cell. Biochem 1981; 39: 261 - 279.

19. Gupta YK, Chaudhary G and Srivastava AK. Protective effect of resveratrol against pentylenetetrazole-induced seizures and its modulation by an adenosinergic system. Pharmacology 2002; 65(3): $170-174$.

20. Orozco-Ibarra M, Muñoz-Sánchez J, Zavala-Medina ME, Pineda B, Magaña-Maldonado R, Vázquez-Contreras $E$, Maldonado PD, Pedraza-Chaverri J, Chánez-Cárdenas ME. Aged garlic extract and S-allylcysteine prevent apoptotic cell death in a chemical hypoxia model. Biol Res. 2016; 49:7.

21. Dinesh Dhingra and Vaibhav Kumar. Evidences for the involvement of monoaminergic and GABAergic systems in antidepressant-like activity of garlic extract in mice. Indian $\mathrm{J}$ Pharmacol. 2008 Aug; 40(4): 175-179.

22. Neeraj Gilhotra, Dinesh Dhingra.GABAergic and nitriergic influence in antianxiety-like Activity of Garlic in Mice.Journal of Applied Pharmaceutical Science 2016; 6(4), pp. 077-085.

\section{Source of Support: Nil.}

Conflict of Interest: None Declared.

Copyright: (c) the author(s) and publisher. IJMRP is an official publication of Ibn Sina Academy of Medieval Medicine \& Sciences, registered in 2001 under Indian Trusts Act, 1882.

This is an open access article distributed under the terms of the Creative Commons Attribution Non-commercial License, which permits unrestricted non-commercial use, distribution, and reproduction in any medium, provided the original work is properly cited.

Cite this article as: Romany Helmy Thabet, Arwa Safar S Alshaibany, Reem Jazaa M Alenezi, Aeshah Marshad A Alanazi. Protective Effect of Garlic Extract Against Pentylenetetrazole Induced Seizures. Int J Med Res Prof. 2016; 2(5):160-64. 